\title{
The Research Foundation of Hospital and Healthcare Administration
}

\section{INTRODUCTION}

The Research Foundation of Hospital and Healthcare Administration has been founded with the aim to function as a scientific body encouraging and assisting research as well as all such activities that are likely to benefit art and science of Hospital Administration and Management in Indian subcontinent.

\section{VISION}

'Learn to lead, lead to learn' The Research Foundation of Hospital and Healthcare Administration (RFHHA) is the leading professional foundation in Hospital and Healthcare Administration in Indian subcontinent that strives to protect and promote the Art of Hospital and Healthcare Administration, facilitate capacity building in Indian subcontinent so that clientele can enjoy quality healthcare and can live, grow and prosper in clean and safe communities. The foundation envisions to develop leaders for the health sector so as to enhance the global competitive edge of our healthcare systems.

\section{MISSION}

'To strengthen management in healthcare through training and research, best practices and transformational initiatives to meet contemporary and future social, economic, ecological, technological challenges by facilitating the exchange of information, experience, research and advocating for policies, programs and practices that will improve health sector'.

\section{Who can be a Member of RFHHA?}

Hospital Administrators, Armed Forces Medical Service Officers, Medical Superintendents, Hospital planners and designers, Hospital Service Engineers, Nursing Administrators of Civil and Armed Forces, Hospital Architects, Dean, Directors, CEOs, VPs, Presidents, Chairman of hospitals. Senior doctors occupying/likely to occupy leadership positions in medical and healthcare organizations. Doctors involved in policy-making, program development and implementation at large hospitals/medical colleges and those responsible for healthcare capacity building, efficiency and excellence in medical service delivery, etc. Students of hospital management are also eligible.

\section{How are You Benefited as Member?}

Interaction with peer group will help you to:

1. Enhance your skill set in the core competencies required to be an effective hospital administrator.

2. Deliver growth by evaluating and more effectively managing your performance value drivers.

3. Confidently make strategic decisions by applying new frameworks in healthcare.

4. Gain fresh insights and perspectives on similar challenges faced by other participants.

5. Benchmark yourself against your peer group across organizations and industries.

\section{Benefits of Associate Member}

1. One CME/Work Shop free for life on first cum first serve basis.

2. Fellowship in Hospital \& Healthcare Administration.

3. Research Grant/Assistance.

4. Free e-journal for life.

5. Free access to RFHHA e-Library: a large number of educational materials for members is free of cost.

6. Daily emails and sms on various contemporary administrative and management issues pertaining to hospital management.

7. Free webinar arranged by RFHHA.

\section{What are the Benefits to Your Organization?}

1. Greater organizational performance.

2. Grooming Healthcare Leaders to assume senior management positions. 
3. Better retention and development of the most talented healthcare workforce.

4. Improve the way your administrators deal with challenges across different organizational requirements.

5. Officials with greater self-awareness of their actions and understanding of the impact of their behavior on the organizational growth result in enhanced organizational productivity.

\section{Conferences held by RFHHA}

1. Healthcare Infrastructure and Medical Technology (HIMT 2011) at AIIMS, New Delhi, India.

2. CME on Patient Safety as National Initiative of Patient Safety (NIPS 4, 5, 6, 7) at AIIMS, New Delhi, India.

3. CME on Patient safety at Jammu Medical college, Jammu, Jammu \& Kashmir, India.

4. Health Executive Development Program on Store Management at AIIMS, New Delhi, India.

\section{TYPES OF MEMBERSHIP}

\section{Lifetime Associate Membership}

Membership Fee: ₹ 8000

\section{Corporate/Institutional Membership}

Membership Fee: ₹ 1,50,000

1. This membership can be availed by big hospitals, institutions or any other organizations interested in the objectives of the RFHHA.

2. The grant of membership and monetary contributions for becoming a corporate member shall be decided by the general body (GB) from time to time, and the said contributions will be credited to the RFHHA account.

3. All privileges of an associate member are applicable for 10 members of the corporate/institution as decided by them. 